\title{
Ensure Quality Assurance for Companies and Institutions
}

\author{
Dr. Boyd L. Summers* \\ Senior Software and Quality Assurance Consultant, BL Summers Consulting.LLC, Florence, Arizona, USA
}

${ }^{\star}$ Corresponding author: Senior Software and Quality Assurance Consultant, BL Summers Consulting.LLC, Florence, Arizona, USA; Email: bl.summers.consulting.llc@gmail.com

Received: January 23, 2019; Accepted: January 26, 2019; Published: February 01, 2019;

Journal for outside or inside quality assurance personnel are trained and chartered to partner with companies and/or institutions instill quality assurance, maintain process and product requirement compliance thru in-house audits and evaluations and to provide oversight.

Vision: Quality is inclusive for creating a community working together and establishes an inspired future for business management, employees and customers.

Mission: Drive the growth of our people and our business through personal and professional development focused on disciplined execution and quality. Processes and Evaluation Audit Steps are:

- Quality Planning

- Perform Audits \& Evaluations

- Record and Report Audit \& Evaluation results to Senior Management, organization and employees.

At the start of each review period, auditors prepare for audit and evaluation planning by identifying contracts and those processes that will be evaluated during that specific review period. The identified contracts and processes evaluated during the review period require the right criteria derived from company and/or institution documentation (or associated plans and procedures). Using criteria derived from the documentation plus plans and procedures provides the performance of the audits and evaluations planned for each month. The purpose of the audits and evaluations ensure that activities and/or tasks are completed as planned and are compliant with approved company and/ or institution contracts, plans and procedures. Performing audits and evaluations includes:

- Review of contracts, plans and procedures to determine and select appropriate evaluation criteria.

- In performing the evaluations, auditors make an assessment as to whether the implemented processes are compliant or noncompliant.

- The auditor identifies an issue or opportunity for improvement, as a result of the audit and evaluation.

- Auditors are not limited to performing only the process audits and evaluations that have been planned for a given month, but can provide improvements outside the audit including discussions and suggestions for companies.
- Auditors to perform company process audits is to verify, analyzed, communicate, and track technical, financial/costs, schedules, contractual, customer, suppliers and external and internal risks to ensure long-term success.

- Interviews with employees and Senior Management to ensure quality assurance is implemented for compliance and promoting a professional environment.

\section{Record and Report Process Audit and Evaluation Results:}

Companies and/or institutions maintain historical records (electronic or paper) such that they accurately reflect the activities and status they represent. Manage configuration and control of audit and evaluation records as required by company requirements are retained records for compliance and use for future improvements. There are other and effective methods for audits and evaluations, but the number one method is to ensure "Quality Assurance is First" and the other methods come in second!

Citation:

Summers BL (2019) Ensure Quality Assurance for Companies and Institutions. $J$ Pharmacol Pharm Res Volume 2(1): 1-1. 